\title{
How to Succeed as an International Horticultural Consultant
}

\author{
Roland Ebel ${ }^{1}$ \\ Faculty of Agricultural Sciences, Universidad Autónoma del Estado de México, Ignacio Allende \\ 225, 50000 Toluca, Mexico \\ Clinton C. Shock \\ Oregon State University Malheur Experiment Station, 595 Onion Avenue, Ontario, OR, 97914
}

Additional index words. extension, facilitation, participation

\begin{abstract}
Although the term consultant is used extensively, the duty of an international horticultural consultant (IHC) lacks precision. We propose that the job of an IHC has many attributes similar to an extension agent in the United States. Accordingly, we highlight the responsibilities of an IHC and put them in a historic and organizational context. Subsequently, we give advice about how to act and behave adequately when going to a new country. We bring in experience from successful IHC and a synopsis of specialist literature. Because we stress the importance of the credibility of an IHC within the farming community he is working with, we emphasize interaction with her/his professional and social environment. An IHC must have a genuine interest in the people being served and their challenges and adequate competence to provide a genuine contribution.
\end{abstract}

Many call themselves an IHC or are labeled this way by their employers. The American Society of Horticultural Science (ASHS) has used the term IHC since the early 1990 s and refers to both full-time consulting and part-time jobs. Accordingly, IHCs are employed by individual producers, commodity groups, governments, international agencies, or universities (Albrijo, 1993). The term nongovernmental organization (NGO) was still rare in the $1990 \mathrm{~s}$, but is indispensable for a contemporary list of employers of IHC.

The question of what an IHC actually does remains. There is little ambiguity regarding the first two words of this profession: an IHC works at least partially abroad, and his job is related to horticulture. A consultant is a person who professionally provides expert advice (Oxford English Dictionary, 2010). According to a representative post, typical activities of a horticultural consultant include visiting horticultural clients on site; identifying their business or technical problems; analyzing yields and financial returns; formulating technical solutions; planning and organizing trials to assess their technological options; preparing operational strategies and business plans; and supporting the infrastructure for processing, storage, and transport. Frequently, an IHC is also expected to write publications, hold presentations, and provide advice regarding regulations (Reed, 2009). This description, undoubtedly, is in line with what a horticultural consultant does in a developed country; indeed, most IHC would

Received for publication 11 May 2017. Accepted for publication 11 July 2017.

This paper is included in conjunction with the papers presented during the 2016 ASHS Annual Conference, Atlanta, GA, as part of the Workshop titled "Seize Your Future Internationally: New Opportunities in Horticultural Consulting."

The authors wish to thank Candace Shock who assisted in the review of the manuscript.

${ }^{1}$ Corresponding author. E-mail: roland.ebel@gmx. com. state that their daily routine is similar to this characterization. However, because IHC commonly work in developing countries, they would also interpret that their responsibilities go beyond giving advice. This is caused by the socioeconomic, educational, and political particularities of farmer communities in developing countries. Thus, the versatile requirements for an IHC depend on the environment where he is working and on the mission.

Considering the technical, didactic, and administrative skills an IHC needs to succeed, their profile is close to those of an extension agent in the United States Cooperative Extension System. Extension is traditionally considered the organized exchange of information and the purposive transfer of skills (Nagel, 1997). The term was born around 1850 in the British universities of Oxford and Cambridge with the intention of reaching broader audiences beyond the students on campus (Jones and Garforth, 1997). Views of agricultural extension have changed over time (Davis and Heemskerk, 2012). Today, it describes all kinds of support for people engaged in agriculture by helping them to make the best possible use of their productive resources (Anderson, 2007; Muyanga and Jayne, 2006).

Historically, farmers have received education, training, and advice from 1) informal communication, 2) individual innovators, 3) nonstate organizations, such as farmers' associations, scientific societies, and universities, 4) commercial enterprises, and 5) the state (Garforth, 2011). Organized advice for farmers already existed in ancient Mesopotamia, Egypt, Greece, Phoenicia, and China. The first modern agricultural extension service was founded in England as the result of the disastrous consequences of the outbreak of the potato blight in the 1840s. In the second half of the 19th century, legislation was passed to improve the state of agriculture through education throughout much of Europe, the United States, Canada, Australia, Japan, and many British colonies. Numerous other countries followed this example in the early 20th century. Extension became then a vehicle for fighting starvation through improving yields. At the end of the century, environmental issues as well as socioeconomic guidance of farmers also became concerns of extension. After a period of neglect, extension regained importance with the economic crisis of 2008 (Anderson, 2007; Azadi and Filson, 2009; Jones and Garforth, 1997).

For decades, the research-extensionfarmer linkage was based on a simple model: "Modern" research results had to be transferred to the "backward" farmer (Nagel, 1997). Nowadays, apart from providing knowledge to improve productivity, extension services are expected to cover a variety of new functions, such as support for smallholder farmers, the management of production and marketing chains, food safety, environmentally sustainable production techniques, multifunctional land use, food security, and the facilitation of learning and negotiation processes (Azadi and Filson, 2009; Leeuwis, 2004a, 2004b). This is particularly true for developing countries, where more than $90 \%$ of the world's nearly one million extension personnel are located (Anderson, 2007).

The most common reason for a government to employ an extension service is to guarantee the food security of its nation. A subsequent purpose is the stimulation of agricultural exports. As of the end of the 20th century, public extension was criticized for being irrelevant to the real needs of farmers and for being too expensive (Azadi and Filson, 2009). A further criticism is that conventional extension ignores nonfarm stakeholders of a food system (Christoplos, 2008). Although women constitute $60 \%$ of the rural population worldwide, only $5 \%$ were receiving extension services (Davis and Heemskerk, 2012).

One answer to ineffective extension has been decentralization, handing over federal authority to branch offices and institutes and/or delegating control to lower levels of government (Rivera and Qamar, 2003). 
Nonetheless, for example in Mexico, decentralized extension continues to be criticized for largely ignoring marginalized farmers (Uscanga and Edwards, 2016). A more radical idea is the total privatization: adapting to market demands, extension would supposedly respond more effectively to the needs of farmers and other value chain actors as if guided by the government (Christoplos, 2008). However, the experience so far shows that for gaining access to rural communities and for helping poor farmers, a central role of the public sector is indispensable to set extension priorities (Azadi and Filson, 2009). In addition, private consultants may consider farmers passive recipients of extension (diffusionist approach) rather than following the now prevailing constructivist concept, where famers learn by building on their own experience (van Mele et al., 2010).

The still practiced top-down training and visit model $(\mathrm{T} \& \mathrm{~V})$ of extension does not fit the constructivist zeitgeist. It was promoted by the World Bank from 1975 to 1995 and consists in the transfer of technical advice through temporary community visits, where extension agents train selected contact farmers, who in turn are expected to educate the rest of the community (Anderson and Feder, 2004; Stewart et al., 2014). The standardized $\mathrm{T} \& \mathrm{~V}$ curriculum largely fails to take into consideration that farmers continuously learn independently, solve problems, and identify new ones (Leeuwis, 2004a). Given the limitations of T\&V, the concept of farmer field schools (FFSs) emerged. FFSs consider the needs of the farmers and train them in participatory research and agroecosystems appraisals. A key drawback of FFS is their high cost (Anderson, 2007). Raintree (1999) notes that all participative approaches to extension cannot entirely substitute classic knowledge transfer, since this would mean withholding relevant information from the farmers and, consequently, limit a community's right to make its own evaluation of available infor mation.

At present, there is a considerable diversity of agricultural extension around the world; but the extension is still absent in many regions. Most countries sustain a centralized governmental approach (eventually with a regional or semiautonomous orientation). Except for the United States, current public extension systems are prevailingly organized under governments rather than under universities (Swanson and Rajalahti, 2010); and the national Departments of Agriculture and Higher Education in these countries commonly do not work intensively with each other, either for rivalry or for legal restrictions.

Although extension has become an object of constant reform (Rivera and Sulaiman, 2009), adoption rates remain relatively low in developing countries (Aker, 2011). Thus, the effectivity of extension is being continuously questioned. A study in the Ivory Coast, for example, indicates that extension had no effect on farmer revenue (Romani, 2003). Apart from a lack of money and infrastructure in many developing countries (which has to be best possible compensated by individual IHC and the organizations behind them), there is also skepticism regarding the knowledge and skills of local extension agents. This is related to poor agent training by the respective governments (Halim and Mozahar, 1997).

To understand the various environments for a job as an IHC, we also must consider the ways to organize and implement extension. Nagel (1997) distinguishes between approaches that target all farmers of an area (Table 1) and those that select clientele following specific criteria (Table 2). In addition, extension can target individual farmers or collectively target the entire community (Labarthe, 2009). We also distinguish three procedures to select the goals of an intervention and/or to validate its achievement: 1) the traditional approach, where the extension agents design the teaching objectives, contents, techniques, and evaluation; 2) the experiential approach, which stresses real or simulated situations in the field; and 3) the performance-based approach, where goals are measured through the attainment of a given level of proficiency (Halim and Mozahar, 1997). Finally, the institution that offers extension is usually also responsible for its operation. In contrast, in self-organization approaches (Klerkx et al., 2010), the implementation of extension depends on the target community. The goal is to enhance the capability of a community to find innovative solutions for future problems and to be able to apply them. This way, the facilitation of learning becomes more relevant than the content itself (Leeuwis, 2004a). Extension can also be directed by close cooperation between an extension agent and growers' association representatives in setting priorities and the growers' associations partially funding the research and extension objectives. The

growers' associations then also facilitate education opportunities. Local groups of influential clientele can represent other interests than growers' associations.

Considering now the individual tasks of an IHC, there are two initial assumptions we would like to make: First, whether they accept it or not, beside their role as technical experts, IHC are also communication and community workers (Leeuwis, 2004a; Nagel, 1997; World Bank, 2007). Second, the tasks as IHC are no longer limited to the transfer of technologies but consist in the facilitation of innovation (Holding, 2002; Klerkx et al., 2010; van Beek, 1997).

An IHC may assume different communication roles (Table 3 ). The required role depends on the mission, and it can also change depending on local needs. The mission also determines the general purpose of an IHC to interact with farmers: 1) providing advice where farmers consciously request counseling or expertise, 2) supporting horizontal (farmer-to-farmer) knowledge exchange, 3) facilitating conflict management, 4) organizing capacity building, or 5) initiating innovation (Leeuwis, 2004a). Regarding the latter, innovation can be stimulated by technology-oriented (TIA) and systemsoriented (SIA) innovation approaches. TIAs are generated by formal research that is transferred to farmers (who play a passive role in the development of innovations). Conversely, SIA are technological and socioorganizational processes to enhance a community's capacity to respond to change. The facilitated skills are discovery based and originate from a joint learning process (Schut et al., 2016).

\section{MATERIALS AND METHODS}

Our recommendations for succeeding as an IHC are based on a study of relevant literature and on the experiences of IHC. This information is based on our own work as IHCs, interactions with other IHC all over the

Table 1. General approaches to extension, respective organizing (directing, funding and delivering) entities and the mode of their operation (adapted from Nagel, 1997).

\begin{tabular}{lcc}
\hline Approach & Organizing entity & Mode of operation \\
\hline $\begin{array}{c}\text { Ministry } \\
\text { based }\end{array}$ & Federal government, particularly & Classical knowledge and skills facilitation \\
Project & Govistry of agriculture & (e.g., T\&V), attending national interests \\
approach & parastatal organizations & Agricultural extension is a crucial element \\
University & State universities with local counties & of extensive rural development programs \\
based & and federal government & teaching and training \\
Animation & Government (support and funding) & Farmers selected by the community \\
rurale & & provide training and supervision \\
\hline
\end{tabular}

Table 2. Specific approaches to extension, respective organizing (directing, funding and delivering) entities, and mode of operation (adapted from Nagel, 1997).

\begin{tabular}{lll}
\hline Approach & \multicolumn{1}{c}{ Organizing entity } & \multicolumn{1}{c}{ Mode of operation } \\
\hline Commodity based & $\begin{array}{c}\text { Government, parastatals, } \\
\text { farmer organizations, } \\
\text { private firms }\end{array}$ & $\begin{array}{c}\text { Profit oriented, centers on the production of } \\
\text { determined crops }\end{array}$ \\
$\begin{array}{l}\text { Commercial service } \\
\begin{array}{l}\text { Client based and } \\
\text { client controlled }\end{array}\end{array}$ & NGO firms & $\begin{array}{l}\text { Profit oriented, centers on the use of a product } \\
\text { Local personalities are identified and assume } \\
\text { leader functions after the withdrawal of NGO }\end{array}$ \\
\hline
\end{tabular}

$\mathrm{NGO}=$ nongovernmental organization 
Table 3. Role of consultants and extension agents depending on the needs for innovative change and the goals and respective roles of client (adapted from Leeuwis, 2004a).

\begin{tabular}{|c|c|c|c|}
\hline Role & Focus of needs & Goal & Role of the client \\
\hline Information expert & Individual change & Problem solution & Active problem owner \\
\hline Counselor & Individual change & Enhancement of problem solving ability & Active problem owner \\
\hline \multirow[t]{2}{*}{ Facilitator } & Individual change & Diffusion of innovations & Active learner \\
\hline & Collective change & Building coherent innovations & Active participant \\
\hline Trainer & Collective change & Supporting organization development and capacity building & Active participant \\
\hline Mediator & Collective change & Conflict management & Stakeholder participant \\
\hline
\end{tabular}

world, and with active members of the International Consultants Working Group (ICON) of the ASHS.

\section{RESULTS AND DISCUSSION}

Results involve 1) requirements to succeed as an IHC, 2) suggestions for implementing the job as an IHC, and 3) recommendations for behavior outside of the work environment.

\section{REQUIREMENTS FOR A SUCCESSFUL IHC}

Some consultants think they have the answers to all the farmers' problems. Unfortunately, their perceptions may not be true (Holding, 2002). The same applies for their role as communicators and innovation facilitators. Although numerous employers emphasize participation and community development, there is a considerable discrepancy between what extension agents eventually do and what they say they do (van Beek, 1997).

To be fair, it must be mentioned that working conditions of extension personnel have deteriorated within the last three decades, while their duties are increasing (Nagel, 1997). These days, extension agents must be technically excellent and highly proficient as educational practitioners, creating an infrastructure that promotes innovation and continuous learning (Davis and Heemskerk, 2012; Liles and Mustian, 2004). The challenge is to offer an expertise that adds to the one that the farmers already have (Leeuwis, 2004a) and fits their needs. Although it is impossible for a single person to meet all the ideal IHC characteristics, we would like to present the most frequently mentioned attributes of a successful IHC (Anderson, 2007; Davis and Heemskerk, 2012; Leeuwis, 2004a; Liles and Mustian, 2004) and group them in four categories.

1. Knowledge and competencies:

- Crop management expertise

- Technical ability to diagnose problems and to deliver appropriate solutions

- Proficiency regarding the processing and marketing of the produced crops

- Management and administration proficiency

- Language skills (if required)

- Knowledge of the philosophy and history of her/his organization
- Understanding of the broader political, social, and cultural context of the community

- Understanding of the local and national economy

- Comprehension of the complexity of livelihood and food systems

- Knowledge regarding the dynamics of learning (especially adult education)

- Knowledge about group dynamics

- Imagination to evaluate the relative importance of potential-limiting factors.

2. Skills and experience:

- Facility planning and designing extension programs

- Excellent analytic skills

- Capacity to lead and coordinate

- Advanced management skills

- Negotiation competencies

- Experience effectively transferring and receiving information

- Experience with presentation techniques, publishing, new media, and IT

- Flexibility when operating an extension program without losing track of its goals

- Capacity to monitor and evaluate the implementation of an extension program

- Ability to evaluate the performance of the participating farmers (if required)

- Ability to interact with individuals and groups, creating effective networks

- Cultural sensitiveness

- Facility to communicate with female farmers and with different stakeholders

- Understanding of transparent accountability

- Appropriate level of assertiveness

- Willingness to accept small incremental changes.

3. Character traits:

- Credibility

- Dedication and diligence

- Leadership

- Curiosity and innovativeness

- Willingness to travel

- Autonomy and flexibility

- Openness, patience, and lack of bias

- Being explicit, straight forward, and accurate

- Skills of observation and listening

- Commitment to the mission and goals of her/his organization.
4. Favorable working conditions:

- Support of authority within one's own organization

- Certain independence in decision making

- Independence from involved stakeholders

- Supportive familiar background.

\section{SUGGESTIONS FOR IMPLEMENTING THE JOB AS AN IHC}

There is excellent specialist advice available about didactic tools an IHC can use to succeed as an innovation facilitator (Garforth, 2011; Klerkx et al., 2010; Labarthe, 2009; Leeuwis, 2004a, 2004b; van Beek, 1997; van Mele et al., 2010; World Bank, 2007). Therefore, we present suggestions in this regard, which are based on our own experience.

1. A successful IHC is an observer. Since crops develop differently in other climates and soils, not everything that works at home will be a success abroad. Instead, a good IHC contemplates the new ecosystem and learns from local farmers. Farmers around the world are good observers and often do independent research to improve their crop production and postharvest handling skills.

2. As an IHC in a developing country, you work with crops familiar to you, but you will always lack the full technology you are accustomed to. Hence, you will learn to improvise. Thanks to this challenge, you usually leave your assignment learning more than what you have provided.

3. The target of innovative change (individual or collective), the procedure to determine goals, and strategies, as well as the approach to generate innovation, do not depend on the IHC, but on the interests and perceptions of her/his employer and the community served (Table 4).

4. An IHC needs to define goals and activities jointly with the farming community, and the broader purpose of innovative change must be clear from the outset. Otherwise, efforts to educate and introduce change can become, at best, a series of group dynamics that entertain farmers, but that do not conclude in a meaningful impact.

5. Print and online publications may contain relevant information for the target 
Table 4. Potential incentives for innovative change as international horticultural consultant, respective targets (individual farmers or communities), determination and evaluation of goals, strategies to enhance innovation, and possible employers according to the incentive.

\begin{tabular}{|c|c|c|c|c|}
\hline Incentive & Target & Goals and evaluation & Stimulation of innovation & Potential employer \\
\hline Innovation generation & Collective & Experiential & Systems oriented & Farmer organizations, parastatals, and NGO \\
\hline $\begin{array}{l}\text { Horizontal knowledge } \\
\text { exchange }\end{array}$ & Collective & Performance based & Systems oriented & Farmer organizations and NGO \\
\hline Conflict management & Collective & Performance based & None & Producers, governments, parastatals, and NGO \\
\hline Capacity building & Collective & $\begin{array}{l}\text { Experiential or } \\
\text { performance based }\end{array}$ & Systems oriented & $\begin{array}{l}\text { Farmer organizations, governments, } \\
\text { parastatals, companies, and NGO }\end{array}$ \\
\hline
\end{tabular}

$\mathrm{NGO}=$ nongovernmental organization.

community-and farmers can understand them. Yet, they may need professional support in terms of structuring and "translating" the respective content to their jargon and learning style. Occasionally, a cultural and linguistic diversity within a target audience may require special attention in this regard (Leeuwis, 2004a).

6. A successful IHC is also a very good listener. Despite manifold available didactic resources, person-to-person communication is still the most important form of information transfer (Nagel, 1997). Local growers and technicians have a wealth of locally pertinent knowledge and through listening, the IHC better understands the local clientele and the realities and constraints within which they operate. An IHC should not only pay attention to official sessions but also listen to what is discussed during casual conversations and at markets, in bars, or during social events (Leeuwis, 2004a).

7. Joint fieldwork or other outdoor activities are one of the best ways to get to know the farmers personally and to learn about their needs and skills.

8. Locations are not neutral: For specific audiences, it may not be practically, culturally, or politically feasible to attend activities in certain locations (Leeuwis, 2004a).

9. The temporal agenda must fit the availability of the target community. Consultant activities should not interfere with indispensable crop management activities or with social events of a farmer community.

10. Good financial planning is essential. Suggested innovative change must be compatible with local farming practices, financial resources, and credit and marketing constraints. Recommendations by an IHC often require (temporal and financial) investments by local farmers and other stakeholders. An IHC should be prepared to demonstrate that such potential investments will provide an adequate return on investment. Yet, it is not necessary for IHC to invest their own money.

11. The selection of cooperating staff is key. The best participative approach becomes discredited through cooperating with ignorant, arrogant, or even discriminating persons. This also applies for partnering organizations.

12. An IHC can stimulate networks using horizontal coordination teams (Chowa et al., 2013). In similar fashion, an IHC needs a developed network of international contacts for input, advice, feedback and, eventually, even support. Networks are generally essential for starting and continuing working as an IHC. Counting on a great curriculum vitae, experience, and solid references is not an adequate ticket for succeeding as IHC: Most NGO and consulting companies value people they know and trust.

13. Sometimes, an IHC may become involved in a conflict of interests between members of the target community and their employer. Under such circumstances, loyalty to one's own organization is usually the adequate position. In any case, one should reflect on the situation thoroughly before articulating an opinion - if needed.

14. Only constant feedback and learning allows continuous improvement of work as an IHC.

\section{ADEQUATE BEHAVIOR OUTSIDE THE WORKING ENVIRONMENT}

We mentioned credibility as a principal trait of a successful IHC. Credibility is earned not only in the workplace. Especially, when working in a small, rural community, one should be aware of an almost permanent observation by the farmer families. Therefore, adequate behavior outside the working environment is as important as doing the job with dedication. We consequently suggest the following:

- Where another language is spoken, it is highly recommended to learn and practice it. This is not only a professional advantage (even if clients understand English, one can also understand the hallway conversations), it is also an act of intercultural respect.

- There is a strong tendency in developing countries to exalt foreign specialists. Newcomers face a high risk of (unconsciously) fitting into the role of a "superior creature." Nonetheless, modesty is the appropriate attitude.
- An IHC should never complain about poor infrastructure. There is no doubt that developing countries are economically worse off than the Western world, which is often visible at their farms, universities, and research stations. Thus, local people do not need to be reminded of short comings.

- Similarly, one should be prepared to face less than ideal housing accommodations from the outset. Once arriving at the work site, it is too late to complain.

- Public discussions on politics and religion should be avoided. If at all, they can take place among very good friends away from work.

- "Doing well by doing good often" makes it attractive for horticultural scientists to engage in IHC activities. However, an IHC cannot solve all problems of a developing country and should focus on her/ his responsibilities.

- One should adapt to the new cultural context but never try to assimilate. Enjoying the new environment (e.g., going for local food) is a prerequisite for a successful stay. Trying to imitate the local culture might turn out ridiculous and does not lend to one's credibility.

- Flexibility is essential. If someone cannot accept changes in proposed game plans and schedules, she/he maybe should look for a different job.

- Finally, the most important rule of all: Keep your private life private! One should always keep in mind that foreigners are judged more strictly in moral matters than locals.

\section{Literature Cited}

Aker, J. 2011. Dial "A" for agriculture: A review of information and communication technologies for agricultural extension in developing countries. Agr. Econ. 42:631647.

Albrijo, G. 1993. Horticultural consulting: A national and international perspective. HortScience 28:503 (abstr.).

Anderson, J.R. 2007. Agricultural advisory services. Work Bank, Washington, DC.

Anderson, J.R. and G. Feder. 2004. Agricultural extension: Good intentions and hard realities. World Bank Res. Obs. 19:41-60.

Azadi, H. and G. Filson. 2009. Comparative study of agricultural extension systems: A systemic view. Outlook Agr. 38:337-347.

Chowa, C., C. Garforth, and S. Cardey. 2013. Farmer experience of pluralistic agricultural 
extension, Malawi. J. Agr. Educ. Ext. 19:147160.

Christoplos, I. 2008. Agricultural advisory services and the market. Overseas Development Institute, London, UK.

Davis, K. and W. Heemskerk. 2012. Investment in extension and advisory services as part of agricultural innovation systems, p. 179-259. In: World Bank. Agricultural innovation systems: An investment Sourcebook. World Bank, Washington, DC.

Garforth, C. 2011. Education, training and extension for food producers. Government Office for Science, Reading, UK.

Halim, A. and A. Mozahar. 1997. Training and professional development, p. 135-142. In: B.E. Swanson, R.P. Bentz, and A.J. Sofranko (eds.). Improving agricultural extension: A reference manual. FAO, Rome, Italy.

Holding, A.C. 2002. Forest extension: Equitable partnerships for sustainable multi-functional forestry. FAO, Valdivia, Chile.

Jones, G.E. and C. Garforth. 1997. The history, development, and future of agricultural extension, p. 13-40. In: B.E. Swanson, R.P. Bentz and A.J. Sofranko (eds.). Improving agricultural extension: A reference manual. FAO, Rome, Italy.

Klerkx, L., N. Aarts, and C. Leeuwis. 2010. Adaptive management in agricultural innovation systems: The interactions between innovation networks and their environment. Agr. Syst. 103:390-400.

Labarthe, P. 2009. Extension services and multifunctional agriculture: Lessons learnt from the French and Dutch contexts and approaches. J. Environ. Mgt. 90:193-202.

Leeuwis, C. 2004a. Communication for rural innovation: Rethinking agricultural extension. 3rd ed. Blackwell Publishing, Oxford, UK.
Leeuwis, C. 2004b. Fields of conflict and castles in the air. Some thoughts and observations on the role of communication in public sphere innovation processes. J. Agr. Educ. Ext. 10:6376.

Liles, R.T. and R.D. Mustian. 2004. Core competencies: A systems approach for training and organizational development in extension. J. Agr. Educ. Ext. 10:77-82.

Muyanga, M. and T. Jayne. 2006. Agricultural extension in Kenya: Practice and policy lessons. Egerton University, Tegemeo Institute of Agricultural Policy and Development, Njoro, Kenya.

Nagel, U. 1997. Alternative approaches to organizing extension, p. 41-63. In: B.E. Swanson, R.P. Bentz, and A.J. Sofranko (eds.). Improving agricultural extension: A reference manual. FAO, Rome, Italy.

Oxford English Dictionary. 2010. Consultant. OED Online. 23 Jan. 2017. <https://en.oxforddictionaries. com/definition/consultant>.

Raintree, J.B. 1999. If $\mathrm{i}$ had a hammer: Some suggestions concerning community forestry at the turn of the century. Regional Community Forestry Training Center, Bangkok, Thailand.

Reed, H. 2009. Occupational profile horticultural consultant. Association of Graduate Careers Advisory Services. 16 Jan. 2017. <http:// 130.88.36.167/p/types_of_job/print/horticultural_ consultant.jsp>.

Rivera, W.M. and M.K. Qamar. 2003. Agricultural extension, rural development and the food security challenge. FAO, Rome, Italy.

Rivera, W.M. and V.R. Sulaiman. 2009. Extension: Object of reform, engine for innovation. Outlook Agr. 38:267-273.
Romani, M. 2003. The impact of extension services in times of crisis: Côte d'Ivoire (1997-2000). University of Oxford, Oxford, UK.

Schut, M., L. Klerkx, M. Sartas, D. Lamers, M. Mc Campbell, I. Ogbonna, P. Kaushik, K. Atta-Krah, and C. Leeuwis. 2016. Innovation platforms: Experiences with their institutional embedding in agricultural research for development. Expt. Agr. 52:537-561.

Stewart, R.L., M. Klerkx, M. Sartas, D. Lamers, M. Campbell, I. Obgonna, P. Kaushik, K. Atta, and C. Leeuwis. 2014. The effects of training, innovation and new technology on African smallholder farmers' wealth and food security: A systematic review. The Campbell Collaboration, Oslo, Norway.

Swanson, B.E. and R. Rajalahti. 2010. Strengthening agricultural extension and advisory systems: Procedures for assessing, transforming, and evaluating extension systems. Agr. Rural Dev. Discuss. Pap. 45:1-186.

Uscanga, J.M. and C. Edwards. 2016. Decentralization of Mexico's agricultural extension services and the ongoing struggle to alleviate rural poverty. J. Intl. Agr. Ext. Educ. 23:14-27.

van Beek, P. 1997. Beyond technology transfer? Eur. J. Agr. Educ. Ext. 4:183-192.

van Mele, P., J. Wanvoeke, C. Akakpo, R.M. Dacko, M. Ceesay, L. Béavogui, M. Soumah, and R. Anyang. 2010. Videos bridging Asia and Africa: Overcoming cultural and institutional barriers in technology-mediated rural learning. J. Agr. Educ. Ext. 16:75-87.

World Bank. 2007. World development report 2008: Agriculture for development. World Bank, Washington, DC. 